\title{
A Framework to Predict Software "Quality in Use” from Software Reviews
}

\author{
Issa Atoum and Chih How Bong \\ Faculty of Computer Science and Information Technology \\ Universiti Malaysia Sarawak \\ 94300 Kota Samarahan, Sarawak, Malaysia \\ \{ Issa.Atoum@gmail.com, chbong@fit.unimas.my \}
}

\begin{abstract}
Software reviews are verified to be a good source of users' experience. The software "quality in use" concerns meeting users' needs. Current software quality models such as McCall and Boehm, are built to support software development process, rather than users perspectives. In this paper, opinion mining is used to extract and summarize software "quality in use" from software reviews. A framework to detect software "quality in use" as defined by the ISO/IEC 25010 standard is presented here. The framework employs opinionfeature double propagation to expand predefined lists of software "quality in use" features to domain specific features. Clustering is used to learn software feature "quality in use" characteristics group. A preliminary result of extracted software features shows promising results in this direction.
\end{abstract}

Keywords: "quality in use”; software reviews; opinion mining; ISO 25010; quality model; product reviews

\section{Introduction}

Online product reviews are a major information source of users' experience. Many online web sites give users the opportunity to share their experience and give ideas about software and possible enhancements. Reviews on popular software have increased dramatically; hence processing them is a laborious yet costly. Moreover, most of the time product reviews can be confusing and misleading. For example, comments like "I just don't like this product" and "The product took forever to be here" is lack of constructive expressions as the comments were not targeted on the product because some reviews consist of emotional expression and/or biases.

Software products are evaluated differently by different stakeholders' interests. For example, the publisher of the product may be interested in developing quality software while users care about the whole product while it is operational. Quality according to Gravin in the point view of a user is "meeting customer needs"[1]. If the software meets the needs then it is said to have good quality. 
Many software quality models such as McCall, Boehm, Dromey and FURUPS [2], [3] are built for quality from development perspective and does not fit to measure software quality from user point of view [4], [5]. For users, the purpose of using software is to help them achieve particular goals, as the effectiveness, efficiency and satisfaction with which users can achieve specified goals in specified environments. ISO/IEC 25010:2011(hereafter ISO 25010) covers the software quality by a model known as Systems and software Quality Requirements and Evaluation (SQuaRE). The ISO 25010 has the "quality in use" model, the focus of this work.

Opinion Mining can be used to identify important reviews and opinions to answer users' queries about quality. The more fine-grain works are on feature or aspect-based sentiment analysis where it determines the opinions on the features of the reviewed entity such as cell phone, tablet etc. More importantly, to our knowledge little research has been published in software reviews opinion mining. Mining software reviews can save users time and can help them in software selection process.

Table 1. definitions of "quality in use " characteristics from ISO 25010.

\begin{tabular}{|c|c|}
\hline Characteristic & Definition \\
\hline Effectiveness & $\begin{array}{l}\text { Accuracy and completeness with which users achieve specified } \\
\text { goals (ISO 9241-11). }\end{array}$ \\
\hline Efficiency & $\begin{array}{l}\text { Resources expended in relation to the accuracy and completeness } \\
\text { with which users achieve goals (ISO 9241-11). }\end{array}$ \\
\hline Freedom From Risk & $\begin{array}{l}\text { Degree to which a product or system mitigates the potential risk to } \\
\text { economic status, human life, health, or the environment. }\end{array}$ \\
\hline Satisfaction & $\begin{array}{l}\text { Degree to which user needs are satisfied when a product or system } \\
\text { is used in a specified context of use. }\end{array}$ \\
\hline Context Coverage & $\begin{array}{l}\text { Degree to which a product or system can be used with effective- } \\
\text { ness, efficiency, freedom from risk and satisfaction in both speci- } \\
\text { fied contexts of use and in contexts beyond those initially explicit- } \\
\text { ly identified. }\end{array}$ \\
\hline
\end{tabular}

This paper proposes a framework to process software user reviews in order to extract one of the software quality indicators, "quality in use" as defined by the ISO 25010 (ISO, 2011). Table 1 shows "quality in use" definitions. Note that these definitions has some intersection with product quality division of the the ISO standard, more precisely the usability characteristic. One major step of this research is to build a data set of software keywords or features. In the context of our study, software features are software properties that describe software "quality in use" such as the keyword conform and resource to describe satisfaction and efficiency characteristics respectively. Once data are in place, then a model is built utilizing topic modeling [6][7] and opinion mining [8] methods. Finally the model is evaluated against predefined criteria with users.

First, the problem is defined. Then related works are presented. After that, the proposed approach is explained. Finally, preliminary results are presented and the paper is concluded. 